\title{
Evidence for TiON sputtered surfaces showing accelerated antibacterial activity under simulated solar irradiation
}

\author{
Sami Rtimi ${ }^{\mathrm{a}, *}$, Cesar Pulgarin ${ }^{\mathrm{a}, *}$, Michael Bensimon $^{\mathrm{b}}$, John Kiwi ${ }^{\mathrm{c}}$ \\ ${ }^{a}$ Ecole Polytechnique Fédérale de Lausanne, EPFL-SB-ISIC-GPAO, Station 6, CH-1015 Lausanne, Switzerland \\ ${ }^{\mathrm{b}}$ Ecole Polytechnique Fédérale de Lausanne, EPFL-ENAC-IIEGR-CEL, Bat GC, Station 18, CH-1015 Lausanne, Switzerland \\ ${ }^{\mathrm{c}}$ Ecole Polytechnique Fédérale de Lausanne, EPFL-SB-ISIC-LPI, Bat Chimie, Station 6, CH-1015 Lausanne, Switzerland
}

Received 14 January 2013; received in revised form 11 March 2013; accepted 28 March 2013

Available online 1 May 2013

Communicated by: Associate Editor Gion Calzaferri

\begin{abstract}
New evidence is reported for TiON sputtered polyester surfaces activated by sunlight irradiation leading to the accelerated bacterial inactivation in the minute range. The absorption in Kubelka-Munk units of the TiON film was observed to be directly proportional to the time of Escherichia coli inactivation as detected by diffuse reflection spectroscopy (DRS). TiON layers were characterized by electron microscopy and by high angle angular dark field (HAADF) showing the continuous coverage of the polyester fibers by the TiON film. $\mathrm{Ti}^{4+} / \mathrm{Ti}^{3+}$ redox catalysis was detected on the TiON surface by the XPS shifts during the bacteria inactivation process. Production of HO radicals on TiON-polyester as a function of sunlight irradiation was determined following the fluorescence of 2-hydroxyterephthalic acid. Release of $\mathrm{Na}$ and $\mathrm{K}$-ions was determined by ICP-MS and provides the evidence that cell wall damage is a preceding step leading the bacterial inactivation. A stable performance of the TiON films was observed during repetitive bacterial inactivation.
\end{abstract}

(c) 2013 Elsevier Ltd. All rights reserved.

Keywords: TiON sputtered surfaces; Simulated solar light; Antibacterial films; OH-radicals; Cell wall damage

\section{Introduction}

The search for more efficient, stable and adhesive antimicrobial nanoparticulate films is a valid research topic since these films are directed to preclude the formation of biofilms leading to hospital acquired infections (HAI) (Thüringer Surface and Biomaterials Kolloquium-Germany, 2011; Dancer, 2009). Films presenting a faster bacterial inactivation are needed at the present time due to the increasing resistance of pathogenic bacteria to synthetic antibiotics when administered for long-times (Kramer et al., 2006; Mills et al., 2012). These biofilms remain stable

\footnotetext{
* Corresponding authors. Tel.: +41 216936150 (S. Rtimi), tel.: +41 216934720 (C. Pulgarin).

E-mail addresses: sami.rtimi@epfl.ch(S. Rtimi), cesar.pulgarin@epfl.ch (C. Pulgarin).
}

for very long periods on a variety of surfaces spreading bacteria by contact in public places or confined to hospital or school rooms. Recently Parkin et al. reported the preparation of antibacterial films of $\mathrm{Ag}, \mathrm{Cu}$, and $\mathrm{TiO}_{2}$ by colloidal methods. Page et al. $(2009,2011)$ and Yates et al. (2008) reported the deposition of films by Physical Vapor Deposition (PVD) mainly on heat resistant materials. $\mathrm{TiO}_{2}, \mathrm{Ag}$, and $\mathrm{Cu}$ films from 6 to $50 \mathrm{~nm}$ have been reported and these thicknesses have been shown to lead an effective bacterial inactivation under UV and in some cases under visible light irradiation. The disadvantages of the PVD deposition approach are the high investment costs, the high temperatures needed precluding film deposition on textiles like the polyester used in the present study and the amount of heat used requiring costly cooling systems.

Our laboratory has focused on antibacterial $\mathrm{Ag}$ and Cu-textiles deposited by DC/DCP and RF magnetron 
sputtering (Baghriche et al., 2012a; Mejia et al., 2010; Kusiak-Nejman et al., 2011). Kelly et al. (2009 and 2010)) has recently reported the antibacterial activity of sputtered nitrides films. Rtimi et al. have reported TiN/ $\mathrm{TiN}-\mathrm{Ag}$ and $\mathrm{ZrN} / \mathrm{ZrN}-\mathrm{Ag}$ film bacterial inactivation in the dark and under visible/actinic low intensity light irradiation (Rtimi et al., 2012a, 2012b; Baghriche et al., 2012b). The innovative objective of the present study is to report on solar induced bacterial inactivation by sputtered TiON films using laboratory scale solar simulators. These TiON films avoid the adverse environmental effects caused by the release of the components of the photocatalyst in the case of the sol-gel method and to avoid the leaching of $\mathrm{Ag}$ as reported by (Geranio et al., 2009).

The surface of the TiON films were characterized by Xray Fluorescence (XRF), profilometry, diffuse reflectance spectroscopy (DRS), electron microscopy (TEM and HAADF), atomic force microscopy (AFM), induced coupled plasma mass spectrometry (ICP-MS) and X-ray photoelectron spectroscopy (XPS).

\section{Experimental section}

\subsection{TiON DC-sputtered, thickness calibration and Ti- content}

The TiON was DC-sputtered on polyester Dacron polyethylene-terephthalate; type 54 spun plain weave ISO $105-\mathrm{F} 04,2 \mathrm{~cm}^{2}$ in size. The residual pressure Pr in the sputtering chamber was set at $\operatorname{Pr} \leqslant 10^{-4} \mathrm{~Pa}$. The substrate target distance was $10 \mathrm{~cm}$. The TiON thin films were deposited by DC-reactive sputtering in a flow of gas containing $\mathrm{Ar}+\mathrm{N}_{2}+\mathrm{O}_{2}$. The target was a Ti-target 99.99\% pure (Kurt J. Lesker, East Sussex, UK) 2 inches in diameter. The total pressure $P_{T}=\left(P_{\mathrm{Ar}}+P_{\mathrm{N} 2}+P_{\mathrm{O} 2}\right)$ was fixed at $0.5 \mathrm{~Pa}$ and the fastest bacterial inactivation kinetics was obtained with a gas composition $\mathrm{Ar} 90 \%: \mathrm{N}_{2} 5 \%: \mathrm{O}_{2} 5 \%$. The current on the Ti target was set at $280 \mathrm{~mA}$, and the power at $128 \mathrm{~W}(\mathrm{U}-518 \mathrm{~V})$. The film thickness was determined with a profilometer (Alphastep500, TENCOR).

The Ti-content on the sputtered polyester was evaluated by X-ray fluorescence (XRF). Each element emits an X-ray of a certain wavelength associated with its particular atomic number in the XRF, PANalytical PW2400 spectrometer.

\subsection{Evaluation of the bacterial inactivation of Escherichia coli}

Escherichia coli $\mathrm{K} 12$, from now on $E$. coli, was obtained from the Deutsche Sammlung GmbH (DSMZ) ATCC23716, Germany. The polyester fabrics were sterilized by autoclaving at $121^{\circ} \mathrm{C}$ for $2 \mathrm{~h}$. The $20 \mu \mathrm{L}$ aliquots of the bacterial culture with a concentration of $\sim 10^{6}$ $\mathrm{CFU} \mathrm{mL} \mathrm{m}^{-1}$ in $\mathrm{NaCl} / \mathrm{KCl}$ were placed on the polyester fabric. These polyester samples were placed on Petri dish provided with a lid to prevent evaporation. After each determination, the fabric was transferred into a sterile $2 \mathrm{~mL}$ Eppendorf tube containing $1 \mathrm{~mL}$ autoclaved $\mathrm{NaCl} /$ $\mathrm{KCl}$ saline solution. This solution was subsequently mixed thoroughly using a Vortex for $3 \mathrm{~min}$. Serial dilutions were made in $\mathrm{NaCl} / \mathrm{KCl}$ solution. The $100 \mu \mathrm{L}$ sample of each dilution was pipetted onto a nutrient agar plate and then spread over the surface of the plate using the standard plate method. Agar plates were incubated lid down, at $37^{\circ} \mathrm{C}$ for $24 \mathrm{~h}$ prior to the counting of the bacterial colonies (Rtimi et al., 2012a, 2012b; Baghriche et al., 2012b). The bacterial data reported were replicated three times. The statistical analysis of the experimental values was compared by oneway analysis.

\subsection{Diffuse reflectance spectroscopy (DRS), transmission electron microscopy (TEM) and atomic force microscopy ( $A F M)$}

Diffuse reflectance spectroscopy (DRS) was determined using a Perkin Elmer Lambda 900 UV-VIS-NIR spectrometer. The absorption of the samples was plotted in Kubelka-Munk (KM/S) units.

A Philips CM-12 (field emission gun, $300 \mathrm{kV}, 0.17 \mathrm{~nm}$ resolution) microscope at $120 \mathrm{kV}$ was used to measure grain size of the Ti-films. The textiles were embedded in epoxy resin 45359 Fluka and the fabrics were cross-sectioned with an ultramicrotome (Ultracut E) and at a knife angle at $35^{\circ}$. High-Angle Annular Dark-Field (HAADF) imaging was used to map the scanning electron microscopy (STEM). These images (Z-contrast images) are obtained by collecting the scattered electrons passing through the objective provided with an annular dark-field detector.

Atomic force microscopy (AFM) of sputtered samples was performed with a Parks Scientific XE120 AFM in contact mode. The Cantilever used was an Olympus OMCLTR400 with a spring constant $0.02 \mathrm{~N} / \mathrm{m}$. Images with a scanning field $600 \mathrm{~nm} \times 600 \mathrm{~nm}$ were taken using a line frequency $2 \mathrm{~Hz}$. The roughness was calculated using Parks' XEI software.

A solar simulator for Hereaus $\mathrm{GmbH}$, Hanau, Germany was used to irradiate the samples with an overall power of $92 \mathrm{~mW} / \mathrm{cm}^{2}$ with light distribution wavelength distribution resembling solar irradiation emitting at wavelengths between 320 and $800 \mathrm{~nm}$.

\subsection{X-ray photoelectron spectroscopy (XPS) and $\mathrm{OH}$ - radical determination}

An AXIS NOVA photoelectron spectrometer (Kratos Analytical, Manchester, UK) equipped with monochromatic $\mathrm{Al} \mathrm{K} \alpha(\mathrm{h} v=1486.6 \mathrm{eV})$ anode was used during the study. The carbon $\mathrm{C} 1 \mathrm{~s}$ line with position at $284.6 \mathrm{eV}$ was used as a reference to correct the charging effects. The surface atomic concentration of some elements was determined from peak areas using known sensitivity factors (Wagner et al., 1979). Spectrum background was subtracted according to Shirley (Shirley, 1972). The XPS spec- 
tra for the Ti-species were analyzed by means of spectra deconvolution software (CasaXPS-Vision 2, Kratos Analytical, UK).

The detection of the oxidative species (mainly OH-radicals) in the TiON sputtered samples was carried out according to Hashimoto (Ishibashi et al., 2000). The terephthalic acid $99 \%$ was obtained from ACROSS. The fluorescence spectrum of the 2-hydroxyterephthalic acid generated by the reaction of terephthalic acid with $\mathrm{OH}$ was measured on a Perkin Elmer LS-50B fluorescence spectrometer

\subsection{Inductively coupled plasma mass spectrometry ( ICPMS)}

The Finnigan ${ }^{\mathrm{TM}}$ ICPMS used was equipped with a double focusing reverse geometry mass spectrometer presenting an extremely low background signal and high iontransmission coefficient. The spectral signal resolution for the $\mathrm{Na}, \mathrm{K}$ and Ti-ions was $1.2 \times 10^{5} \mathrm{cps} / \mathrm{ppb}$ and the detection limit of $0.2 \mathrm{ng} / \mathrm{L}$.

\section{Results and discussion}

\subsection{Coating thicknesses in relation to bacterial inactivation}

Profilometry was carried out for DC sputtered films in a reactive gas atmosphere of $\mathrm{Ar} 90 \%: \mathrm{N}_{2}$ 5\%: $\mathrm{O}_{2}$ 5\%. Four min sputtering time lead to TiON films with a thickness of $\sim 70 \mathrm{~nm}$ and induce the fastest bacterial inactivation. A $70 \mathrm{~nm}$ film contains $\sim 350$ layers. Each layer contains $\sim 10^{15}$ atoms $/ \mathrm{cm}^{2}$ deposited at a rate of $\sim 7.210^{15}$ atoms/ $\mathrm{cm}^{2} \mathrm{~s}$ (Mathews, 1975). Fig. 1 shows the atomic deposition rate as a function of $\mathrm{O}_{2} / \mathrm{N}_{2}$ ratio. The Ti-content on the polyester was evaluated by X-ray fluorescence (XRF). Ti sputtered for $4 \mathrm{~min}$ deposited a $0.39 \%$ Ti by weight on the polyester inactivating bacteria within $40 \mathrm{~min}$ (see

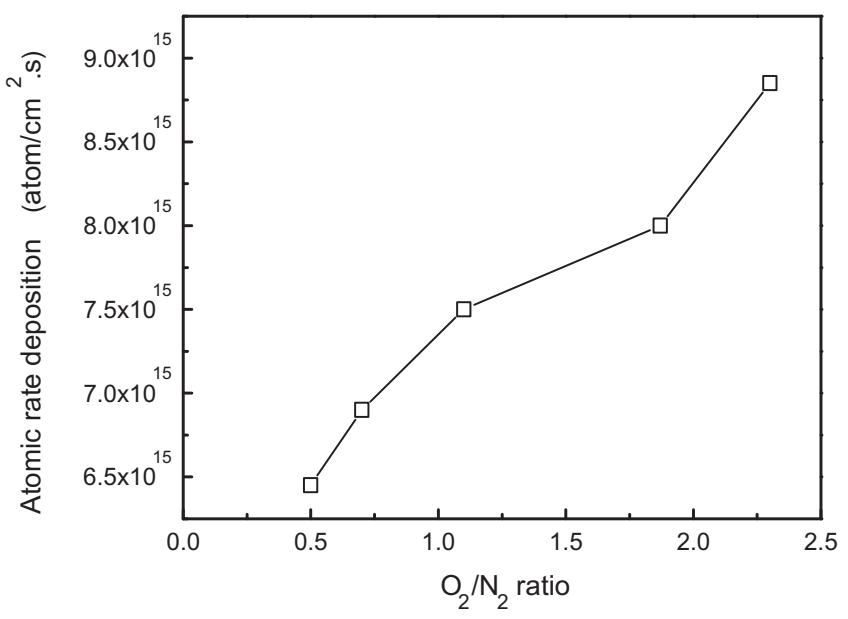

Fig. 1. Atomic deposition rate of TiON films on polyester as a function of the reactive gas $\mathrm{O}_{2} / \mathrm{N}_{2}$ ratio. Ar gas flow was $90 \%$ of the total and working pressure $0.5 \mathrm{~Pa}$.

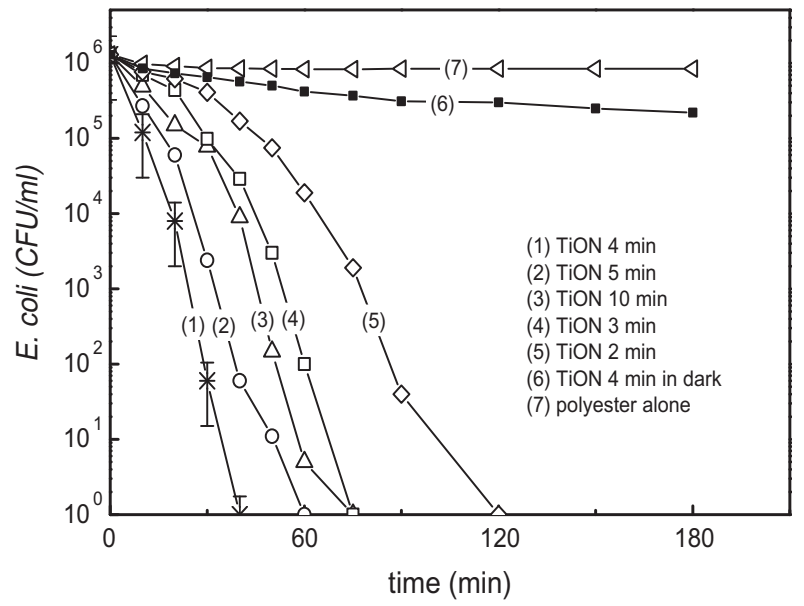

Fig. 2. E. coli inactivation on TiON sputtered on polyester for: (1) 4 min, (2) $5 \mathrm{~min}$, (3) $10 \mathrm{~min}$, (4) $2 \mathrm{~min}$, (5) $1 \mathrm{~min}$, (6) TiON 4 min in dark and (7) polyester alone and irradiated by a Suntest Xenon lamp (310-700 nm). The reactive gas flow composition: $\mathrm{Ar} 90 \%: \mathrm{N}_{2} 5 \%: \mathrm{O}_{2} 5 \%$ and total $P=0.5 \mathrm{~Pa}$.

Fig. 2). The Ti-content on the polyester sputtered for $2 \mathrm{~min}$ and $10 \mathrm{~min}$ on polyester were $0.21 \%$ and $0.55 \% \mathrm{Ti}$ by weight respectively.

Irradiation of the samples during the bacterial inactivation was carried out with a Suntest cavity provided with Xenon lamp with an emission spectrum between 320 and $700 \mathrm{~nm}$. Fig. 2 shows the bacterial inactivation kinetics as a function of the TiON sputtering time. The bacterial inactivation becomes faster at longer sputtering times up to $4 \mathrm{~min}$. Beyond $4 \mathrm{~min}$ sputtering time the reverse trend is observed in Fig. 2 for sputtering times of 5 and $10 \mathrm{~min}$. The slowing down in the bacterial inactivation above $4 \mathrm{~min}$ (70 nm layer thickness) may be due to the fact that thicker coatings lead to bulk inward diffusion of the charge carriers diffusing from the TiON (Mills et al., 2012; Ishibashi et al., 2000) and a decrease in amount of active sites held in exposed interacting with the bacteria (Baghriche et al., 2012a; Castro et al., 2010). Besides these considerations, longer sputtering times may induce TiON inter-particle growth decreasing the TiON contact surface area with bacteria.

\subsection{DRS, TEM and AFM of the TiON samples}

Fig. 3 shows the TiON plasmon resonance occurring in the UV region in agreement with a recent study (Subramanian et al., 2011). The optical absorption of the TiON samples increases with longer sputtering times up to 4, $5 \mathrm{~min}$. Increasing the sputtering times from 1 to 5 min in Fig. 3 lead to TiON samples with a higher optical absorption (Subramanian et al., 2011) due to the introduction of Ninterstitial sites doping the $\mathrm{TiO}_{2}$ with $\mathrm{O}$-vacancies (Valentin et al., 2005). This in turn leads to a larger amount charge transfer sites in the visible region (Lin et al., 2005; Lee et al., 2009). Samples sputtered for 4 and 5 min are seen to present a similar optical absorption indicating satura- 


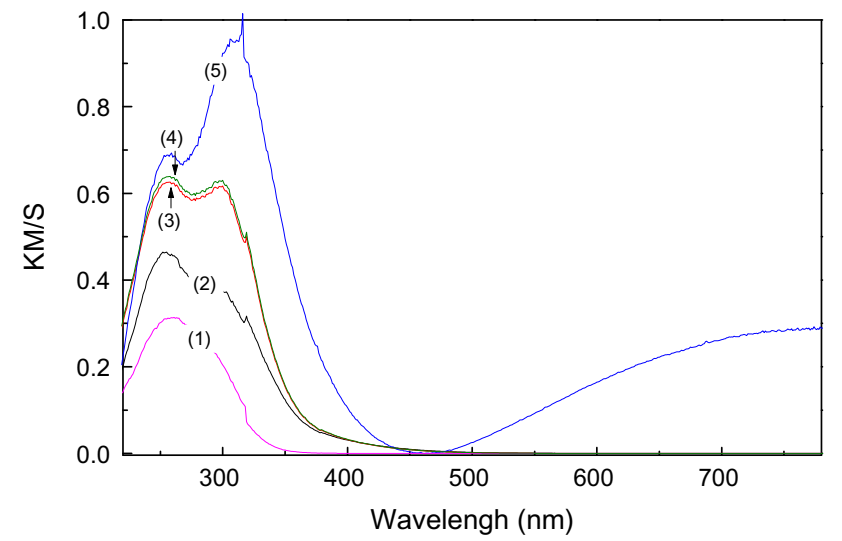

Fig. 3. Diffuse reflectance spectra of TiON samples sputtered on polyester for different times: (1) $1 \mathrm{~min}$, (2) $2 \mathrm{~min}$, (3) $4 \mathrm{~min}$, (4) $5 \mathrm{~min}$ and (5) $10 \mathrm{~min}$.

tion of the polyester surface by the sputtered TiON layers. This suggestion seems to be confirmed by the lack of further growth in the optical absorption by the samples sputtered for 10 min showing additionally a different shape for the TiON spectra. This is due to the non-linear optics introduced by the high density of TiON layers on the polyester surface not following quantitatively the normal trend expected optical absorption increases beyond the saturation concentration (Nadtochenko and Kiwi, 1997).

Fig. 4 shows the TEM of the TiON samples sputtered for 4 min showing a continuous coverage by the TiON on a polyester fiber in the upper two micrographs taken with different magnifications. The TiON layer is seen to beabout $110-125 \mathrm{~nm}$ wide. The three lower images shown in Fig. 4 map the Ti, $\mathrm{O}$ and $\mathrm{N}$ distribution in the TiON particles contrasted by high angular annular dark field (HAADF). On the Ti particles 20-25 nm show a regular surface distribution of $\mathrm{O}$ and $\mathrm{N}$ is shown by these images. The nanoparticulate nature of the film favors the fast bacterial inactivation kinetics shown in Fig. 2 since photocatalsts with a large surface area per unit mass facilitate the charge transfer. The TiON particulate film did not present cracks. The uniformity of the film allows the bacterial adhesion preceeding the bacterial inactivation (Mejia et al., 2010; Kusiak-Nejman et al., 2011; Kiwi and Nadtochenko, 2004; Pulgarin et al., 2012). The transfer of charge between the TiON film and the E. coli depends on the length of the charge diffusion photo-generated in the TiON. This charge diffusion is known to be a function of the particle size and shape of the TiON particles (Mills et al., 2012; Page et al., 2009). The transfer charge generated at the surface of the photocatalyst was reported by Wang et al. (2003) showing that there is no difference in catechol- $\mathrm{TiO}_{2}$ nanoparticle charge transfer (CT) complex and an intra-molecular CT complex. Both complexes show similar CT bands, suggesting a similar donor (catechol) and acceptor (Ti) orbitals in the CT transition.

Fig. 5 shows the atomic force microscopy of TiON sputtered for different times. The TiON sputtered for $4 \mathrm{~min}$ show grains $70-80 \mathrm{~nm}$ in size with a rugosity value (rms) of $0.33 \mathrm{~nm}$. The TiON sputtered for 2 min show grains $30-40 \mathrm{~nm}$ in size with a rugosity value $(\mathrm{rms})$ of $0.24 \mathrm{~nm}$ and finally a rugosity of $0.86 \mathrm{~nm}$ was detected for TiON particles sputtered for $10 \mathrm{~min}$ presenting sizes $\sim 110$ $120 \mathrm{~nm}$. The rms values found indicate a low surface rigidity $(<2.5 \mathrm{~nm})$ and therefore it is unlikely that the roughness variation between the samples will have a significant effect on the bacterial inactivation kinetics. As it was indicated above in Section 3.1, the size of TiON particle, layer thickness and amount of exposed the TiON catalytic sites seem to be the controlling parameters for the bacterial inactivation kinetics reported in Fig. 2.

\subsection{XPS, redo shift of Ti as detected by XPS. Quantification of the OH-radical generation on Ton-polyester}

Fig. 6a presents the XPS spectra of TiON sputtered for $4 \mathrm{~min}$ at time zero of the bacterial inactivation process. Fig. $6 \mathrm{~b}$ shows the XPS spectra for the Ton sample after completion of the solar light induced bacterial inactivation. The TiON deconvolution shows a peak at $458.2 \mathrm{eV}$ for the Ti2 $\mathrm{p}_{3 / 2}$ deconvoluted doublet at time zero and of $458.7 \mathrm{eV}$ after bacterial inactivation. The observed shift in the Ti2 $\mathrm{p}_{3 /}$ ${ }_{2}$ shift position is the evidence for a $\mathrm{Ti}^{3+} / \mathrm{Ti}^{4+}$ redox reaction occurring during bacterial inactivation. XPS shifts $\geqslant 0.2 \mathrm{eV}$ reflect a valid change in the oxidation state (Shirley, 1972). The $\mathrm{Ti}^{3+}$ formation resulting from electrons trapping close to the conduction band was not because of the presence of the bacteria but due to the irradiation reaching the photocatalyst surface. The oxidation of $E$. coli during the bacterial inactivation is reflected in a shift of the O1s shown in Fig. 6c within 40 min from $530.5 \mathrm{eV}$ to $530.5 \mathrm{eV}$, due to the formation to highly oxidized moieties containing carbonyl groups, aldehydes and carboxylic acids before the final oxidation of the bacteria to $\mathrm{CO}_{2}$ (Thüringer Surface and Biomaterials Kolloquium-Germany, 2011; Mills et al., 2012; Page et al., 2009; Kiwi and Nadtochenko, 2004; Pulgarin et al., 2012; Ollis and Ekabi, 1993; Blake et al., 1999; Pitter and Chudoba, 1990).

Table 1 shows the change in the surface atomic concentration of the elements on the TiON sample during $E$. coli inactivation. The O1s signal is seen to increase modestly within the $E$. coli inactivation time as the oxidized residues of the bacteria deposit in the surface of the TiON film. The $\mathrm{Ti} 2 \mathrm{p}_{3 / 2}$ peak intensity was remains stable indicating the availability of the $\mathrm{TiO}_{2}$ on the catalyst surface at all times within the E. coli inactivation. This indicates a rapid removal of the bacterial residues on the catalyst surface during the bacterial inactivation process. The same effect is found for the N-produced during the bacterial decomposition being removed effectively from the catalyst surface. The slow increase in the $\mathrm{C} 1 \mathrm{~s}$ signal with the bacterial inactivation time involves the adventitious hydrocarbons being spontaneously adsorbed from ambient air on the sample surface.

The terephthalic acid (TA) has been reported to react with OH-radicals yielding 2-hydroxyterephthalic acid $(\mathrm{TAOH})$. This later compound presents a fluorescence 

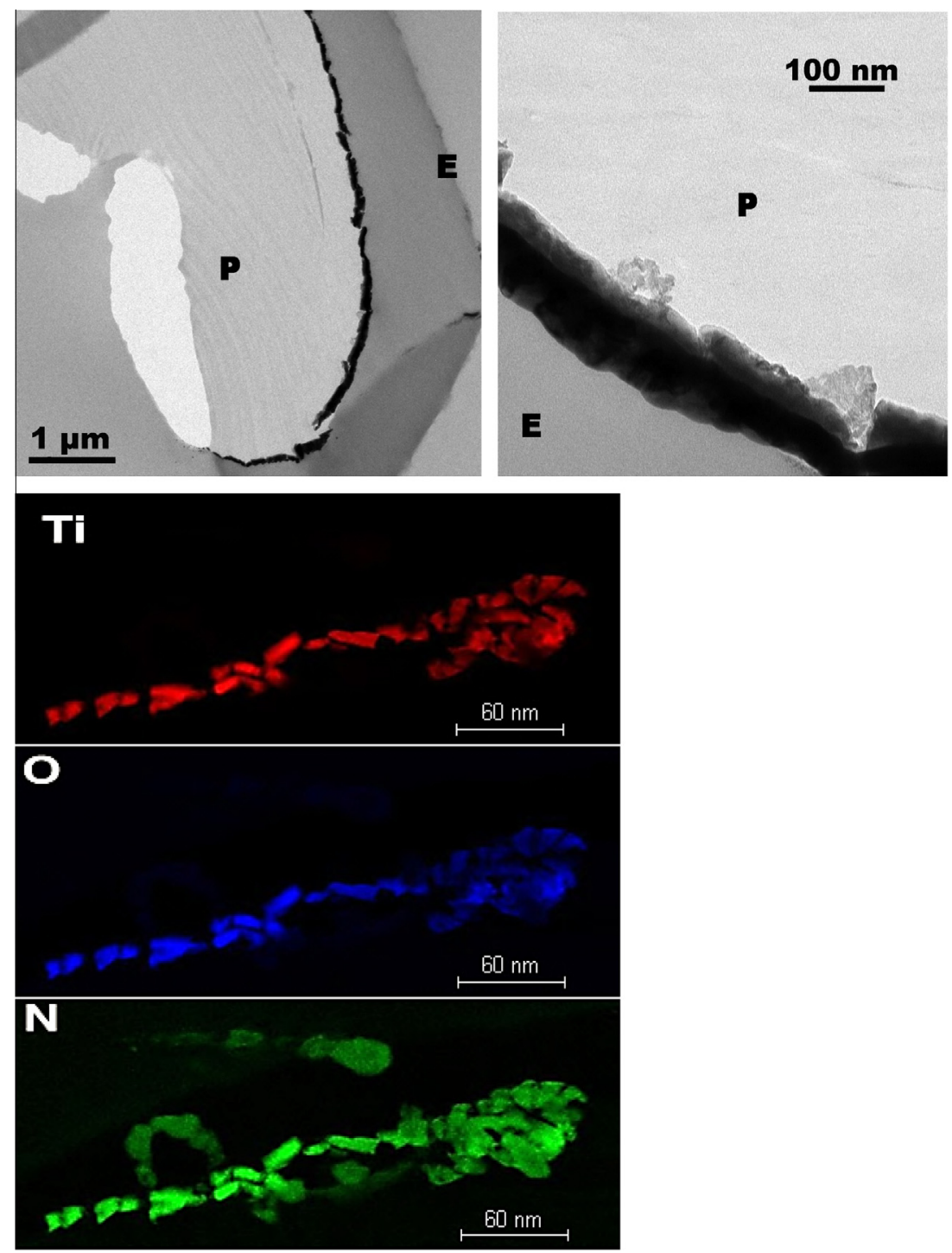

Fig. 4. The upper figures show the TEM of a TiON sample sputtered for 4 min on a polyester fiber taken with two different magnification scales. P: polyester and E: epoxide used in the preparation of the sample for the TEM. The three inserts show the high-angle annular dark field images (HAADF) of the TiON 4 min sputtered sample mapping Ti, $\mathrm{O}$ and $\mathrm{N}$ by $\mathrm{Z}$-contrast imaging.

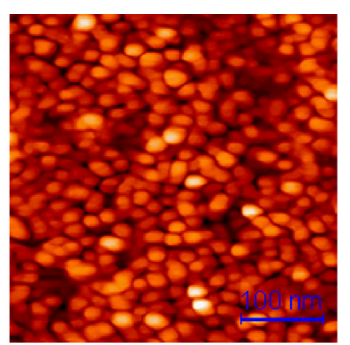

$\mathrm{TiO}_{2}(1 \mathrm{~min})$

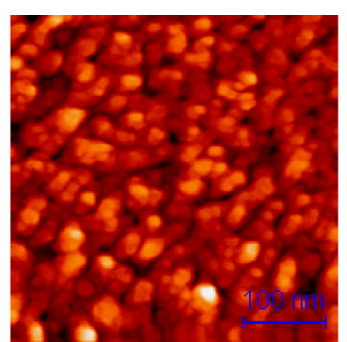

$\mathrm{TiO}_{2}(4 \mathrm{~min})$

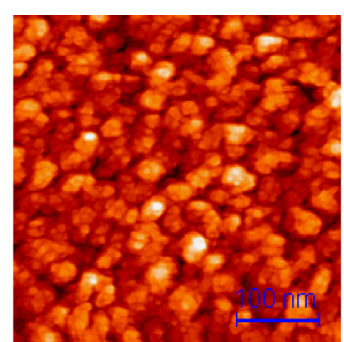

$\mathrm{TiO}_{2}(10 \mathrm{~min})$

Fig. 5. Atomic force microscopy (AFM) of TiON samples sputtered for different times $(600 / 600 \mathrm{~nm})$. For other details see text.

band at $426 \mathrm{~nm}$ upon excitation at $315 \mathrm{~nm}$ (Ishibashi et al., 2000). The $\mathrm{OH}$-radical detection is based on the fact that the intensity of the TAOH peak is proportional to the OH-radicals generated by the TiON-polyester. Fig. 7 shows the fluorescence intensity between 5 and $45 \mathrm{~min}$. This is the time of bacterial inactivation (see Fig. 2).
The mechanism for the generation of the OH-radicals upon solar simulated light irradiation of $\mathrm{TiON} / \mathrm{TiO}_{2}$ leading to bacterial inactivation is suggested below in agreement with accepted knowledge in this area (Mills et al., 2012; Rtimi et al., 2012a; Subramanian et al., 2011; Ollis and Ekabi, 1993; Heefner, 1982) 


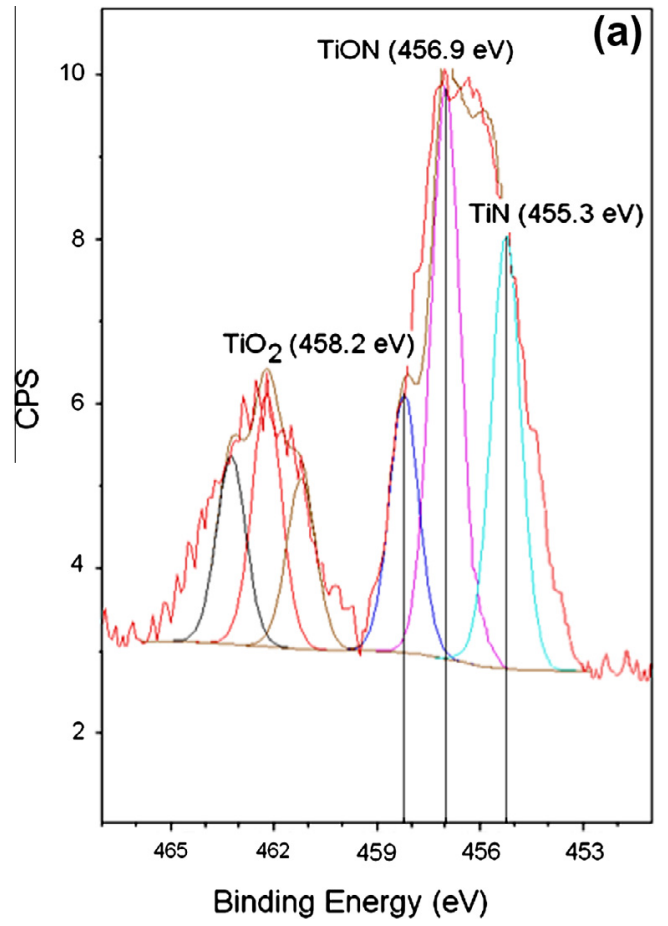

Fig. 6a. Deconvolution spectrum of a TiON 4 min sputtered sample before bacterial inactivation showing the $\mathrm{TiO}_{2}, \mathrm{TiON}$ and $\mathrm{TiN}$ peaks.

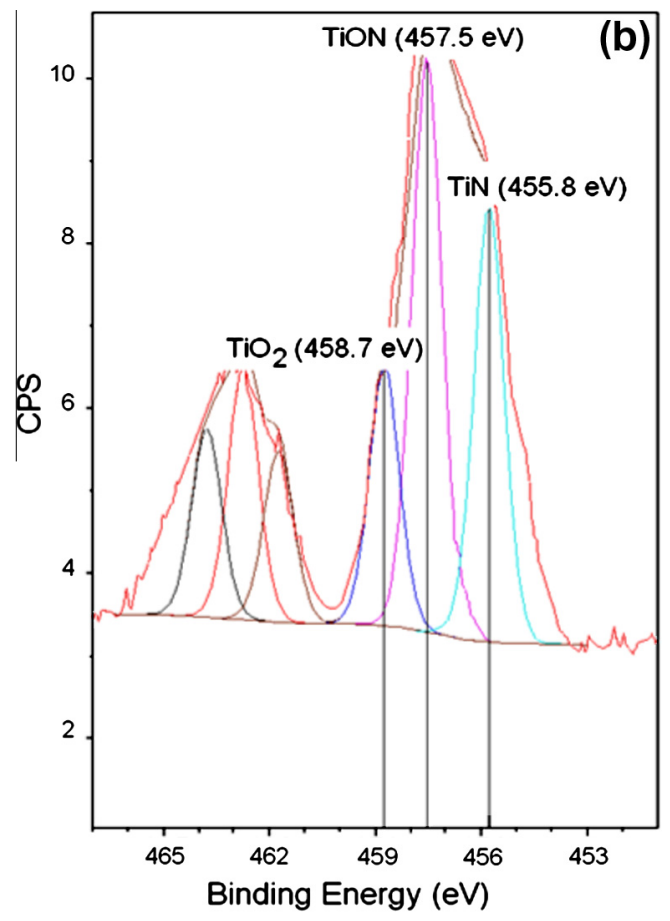

Fig. 6b. Deconvolution spectrum of a TiON 4 min sputtered sample after the $40 \mathrm{~min}$ bacterial inactivation showing the $\mathrm{TiO}_{2}, \mathrm{TiON}$ and $\mathrm{TiN}$ peaks.

$\mathrm{TiO}_{2}+\mathrm{h} v \rightarrow \mathrm{h}^{+}+e^{-}$

$\mathrm{h}^{+}+\mathrm{H}_{2} \mathrm{O} \rightarrow \mathrm{HO}^{\cdot}+\mathrm{H}^{+}$

$\mathrm{h}^{+}+\mathrm{OH}^{-} \rightarrow \mathrm{HO}^{\circ}$

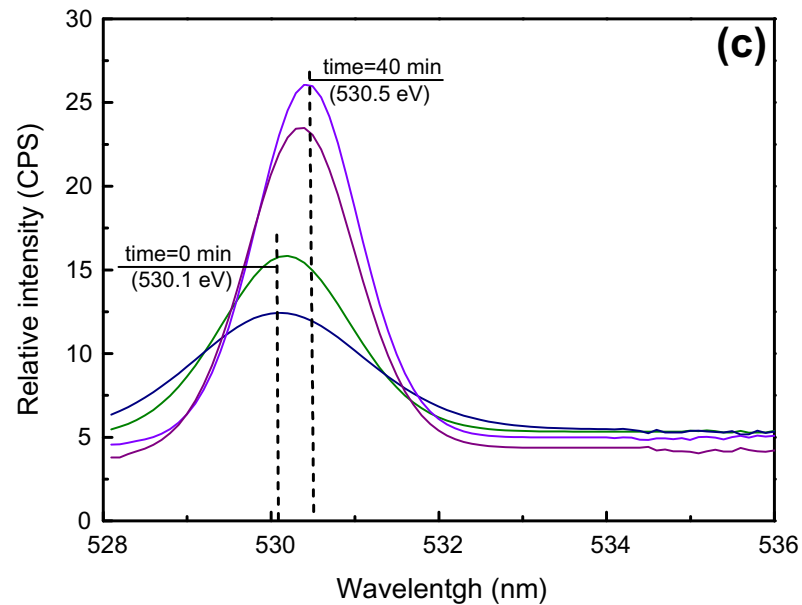

Fig. 6c. O1s XPS signal before and after the $40 \mathrm{~min}$ E. coli inactivation.

Table 1

Surface atomic concentration of elements during $E$. coli inactivation on TiON polyester sputtered sample (4 min) under sunlight simulated light.

\begin{tabular}{lllll}
\hline (TiON sputtered for 4 min) & O1s & Ti2p & N1s & C1s \\
\hline Contacted 3s with bacteria & 17.15 & 22.01 & 11.44 & 27.70 \\
$t=20 \mathrm{~min}$ & 19.09 & 22.51 & 13.02 & 34.22 \\
$t=40 \mathrm{~min}$ & 22.55 & 21.86 & 12.07 & 29.76 \\
\hline
\end{tabular}

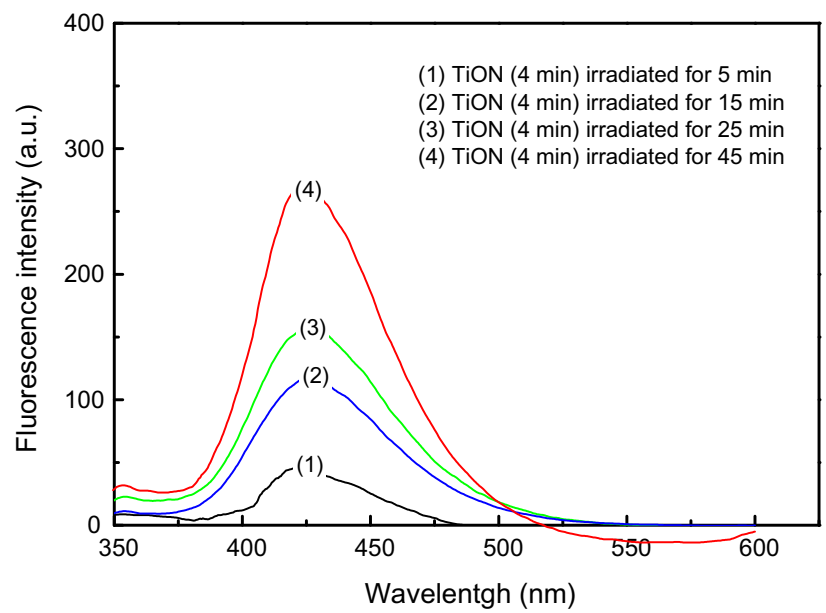

Fig. 7. Fluorescence intensity $v s$ wavelength as a function of irradiation time for TiON sputtered polyester samples irradiated by Suntest sunlight simulator with an overall radiation of $92 \mathrm{~mW} / \mathrm{cm}^{2}$.

$\mathrm{e}^{-}+\mathrm{O}_{2} \rightarrow \mathrm{O}_{2}^{--}$

$\mathrm{O}_{2}^{--}+\mathrm{H}^{+} \rightarrow \mathrm{HO}_{2}^{:}$

$2 \mathrm{HO}_{2} \rightarrow \mathrm{O}_{2}+\mathrm{H}_{2} \mathrm{O}_{2}$

$\mathrm{H}_{2} \mathrm{O}_{2}+\mathrm{O}_{2}^{--} \rightarrow \mathrm{HO}^{\cdot}+\mathrm{OH}^{-}+\mathrm{O}_{2}$

$\mathrm{HO}^{*}+$ bacteria $\rightarrow$ inactivated bacteria 


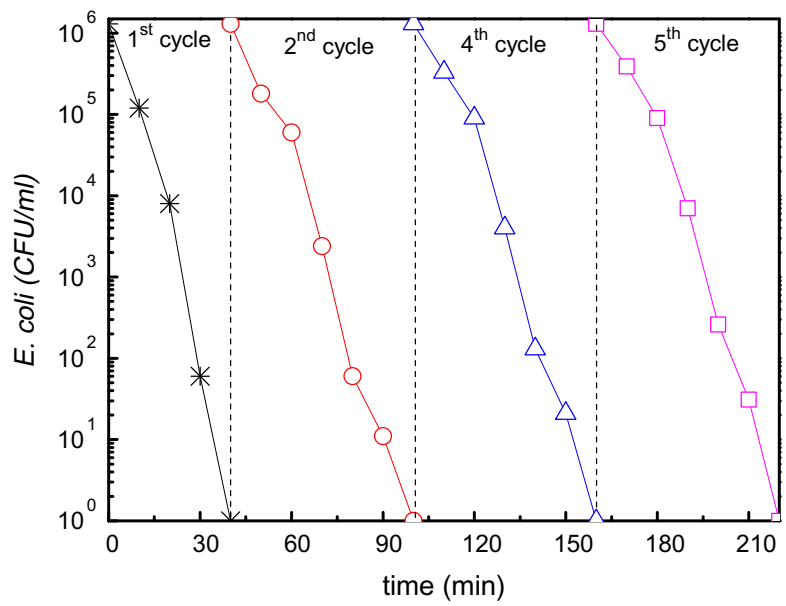

Fig. 8. Recycling TiON sputtered on polyester for 4 min irradiated with the Suntest solar simulator.

Neither the vb holes (Eqs. (1)-(3)) nor the OH-radicals (Eqs. 2, 3, and 7) holes degrade polyester during the photo-induced bacterial inactivation. The stable repetitive E. coli inactivation in Fig. 8 shows repetitive bacterial inactivation on polyester not leading to polyester degradation.

\subsection{Repetitive cycling of TiON-polyester and ion-release by E. coli during bacterial inactivation}

Fig. 8 shows the stable recycling of the TiON-polyester sample up to the 5th cycle. The sample was thoroughly washed after each recycling. The TiON chemical state therefore does not change after each inactivation cycle. Further testing of the catalyst kinetics leading to the complete $E$. coli inactivation seem to be necessary to determine the catalyst stability over longer operational times.

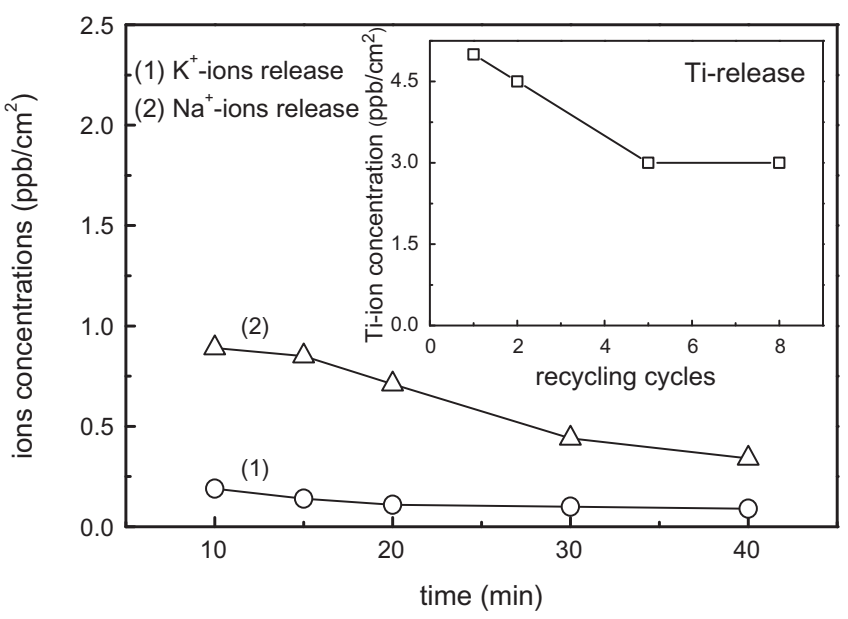

Fig. 9. Ion-coupled plasma mass spectrometry (ICP-MS) determination of the leakage of (1) $\mathrm{K}^{+}$and (2) $\mathrm{Na}^{+}$-ions through the E. coli cell wall during bacterial inactivation by a TiON 4 min samples irradiated by a Suntest solar simulator. The insert shows the Ti-ions release during the sample recycling after $1,3,5$, and $8 E$. coli inactivation cycles.
By ICP-MS spectrometry, the $\mathrm{K}$, Na-ions released by the bacteria within the 40 min inactivation time was determined and related to the Ti-release from the sputtered polyester. The results are shown in Fig. 9. The $\mathrm{K}^{+}$-ions leak at a relative low concentration through the bacterial cell wall membrane becoming more permeable up to 30 min. These $\mathrm{K}^{+}$-ions are known to be important regulators of the cell-wall redox potential (Hirakawa and Nosaka, 2002). The $\mathrm{Na}^{+}$-ions present at a higher initial concentration leaked at a higher rate up to $40 \mathrm{~min}$ due to their smaller size compared to the $\mathrm{K}^{+}$-ions. The cell wall permeability increase of $E$. coli preceding inactivation occurs within $40 \mathrm{~min}$, the time of bacteria inactivation (Kiwi and Nadtochenko, 2004; Pulgarin et al., 2012) (see Fig. 2). Reports have addressed cell wall repair during the culture of the cells on the agar plates increasing the time necessary for complete bacterial inactivation (Huang et al., 2000; Pigeot-Rémy et al., 2011).

\section{Conclusions}

This study shows TiON films on polyester leading to an accelerated bacterial inactivation under simulated solar irradiation. The potential practical application of solar energy by these films is a valid alternative to preclude biofilm formation spreading harmful bacteria. TiON bactericide films have the potential to replace Ag-based disinfection materials leaching undesirable Ag-metal into the environment. Evidence is presented by XPS spectroscopy for the stable performance for the TiON films under solar simulated irradiation triggering the rapid destruction of the residual fragments on the TiON film left by bacterial inactivation.

\section{Acknowledgment}

We thank the COST Action MP0804, the COST Action MP1106, the EPFL, the LIMPID FEP 7 EU Project "Nanocomposite Materials for Photocatalytic Degradation of Pollutants NMP 2012.2.2.2-6 (n. 310177)" and the Swiss Hungarian Cooperation Program "Sustainable fine chemicals pharmaceutical industry: screening and utilization of liquid waste" support of this work.

\section{References}

Baghriche, O., Ehiasarian, A., Kusiak-Nejman, E., Morawski, A., Pulgarin, C., Sanjines, R., Kiwi, J., 2012a. High power impulse magnetron sputtering (HIPIMS) and traditional pulsed sputtering (DCMSP) Ag-surfaces leading to E. coli inactivation. J. Photochem. Photobiol. A 227, 11-17.

Baghriche, O., Kiwi, J., Pulgarin, C., Sanjinés, R., 2012b. Antibacterial $\mathrm{Ag}-\mathrm{ZrN}$ surfaces promoted by subnanometric $\mathrm{ZrN}$-clusters deposited by reactive pulsed magnetron sputtering. J. Photochem. Photobiol. A $229,39-45$

Blake, D.M., Maness, P.C., Huang, Z., Wolfrum, E.J., Huang, J., 1999. Application of the photocatalytic chemistry of titanium dioxide to disinfection and the killing of cancer cells. Sep. Purif. Methods 28, 1-50.

Castro, C., Sanjines, R., Pulgarin, C., Osorio, P., Giraldo, S., Kiwi, J., 2010. Structure-reactivity relations for DC-magnetron sputtered 
Cu-layers during $E$. coli inactivation in the dark and under light. J. Photochem. Photobiol. A 216, 295-302.

Dancer, S., 2009. The role of the environmental cleaning in the control of hospital acquired infections. J. Hosp. Infect. 73, 378-386.

Geranio, L., Heuberger, M., Nowack, E., 2009. The Behavior of Silver Nanotextiles during Washing. Environ. Sci Technol. 43, 8113-8118, and references therein about the Ag-leaching problem.

Heefner, L., 1982. Transport of $\mathrm{H}^{+}, \mathrm{K}^{+}, \mathrm{Na}^{+}$and $\mathrm{Ca}^{2+}$ in spretococcus Moll. Cell. Biochem. 44, 81-89.

Hirakawa, T., Nosaka, Y., 2002. Properties of $\mathrm{O}_{2}^{-}$and $\mathrm{OH}$. formed in $\mathrm{TiO}_{2}$ aqueous suspensions by photocatalytic reaction and the influence of $\mathrm{H}_{2} \mathrm{O}_{2}$ and some ions. Langmuir 18, 3247-3254.

Huang, C., Maness, D., Blake, D., Wolfrum, E., Smolinski, E., Jacoby, W., 2000. Bactericide mode of $\mathrm{TiO}_{2}$ photocatalysis. J. Photochem. Photobiol. A 130, 163-170.

Ishibashi, K., Fujishima, A., Watanabe, T., Hashimoto, K., 2000. Detection of active oxidative species in $\mathrm{TiO}_{2}$ photocatalysis using the fluorescence technique. Electrochem. Commun. 2, 207-210.

Kelly, P., Li, H., Whitehead, K., Verran, J., Arnell, R., Iordanova, I., 2009. A study of the antimicrobial and tribological properties of TiN/ Ag nanocomposite coatings. Surf. Coat. Technol. 204, 1137-1141.

Kelly, P., Li, H., Benson, P., Whitehead, K., Verran, J., Arnell, R., Iordanova, I., 2010. Comparison of the tribological and antimicrobial properties of $\mathrm{CrN} / \mathrm{Ag}, \mathrm{ZrN} / \mathrm{Ag}$, TiN/Ag, and TiN/Cu nanocomposite coatings. Surf. Coat. Technol. 205, 1606-1610, and references therein.

Kiwi, J., Nadtochenko, V., 2004. New Evidence for $\mathrm{TiO}_{2}$ Photocatalysis During Bilayer Lipid Peroxidation Leading to Bacterial Cell Wall Damage. J. Phys. Chem. B 108, 17675-17684.

Kramer, A., Schwebke, I., Kampf, G., 2006. How long do nosocomial pathogens persist in on inanimate surfaces? BMC Infect. Diseases 6, 137-146.

Kusiak-Nejman, E., Morawski, A., Ehiasarian, A., Baghriche, O., Pulgarin, C., Mielczarski, E., Mielczarski, J., Kulik, A., Kiwi, J., 2011. E. Coli inactivation by high power impulse magnetron sputtered (hipims) Cu-surfaces. J. Phys. Chem. C. 115, 21113-21119.

Lee, S., Yamasue, E., Okumura, H., Ishihara, K., 2009. Effect of oxygen and nitrogen concentration of nitrogen doped $\mathrm{TiO}_{x}$ film as photocatalyst prepared by reactive sputtering. Appl. Cat. A 371, 179-190.

Lin, Z., Orlov, M., Lambert, C., Payne, J., 2005. New insights into the origin of visible light photocatalytic activity of nitrogen-doped and oxygen-deficient anatase $\mathrm{TiO}_{2}$. J. Phys Chem. B 109, 20948-20952.

Mathews, J., 1975. J Epitaxial Growth Part B, IBM Thomas Watson Research Center. Academic Press, New York, pp. 382-436.

Mejia, I.M., Marín, M., Sanjines, R., Pulgarin, C., Mielczarski, E., Mielczarski, J., Kiwi, J., 2010. Magnetron-sputtered ag-modified cotton textiles active in the inactivation of airborne bacteria, acs appl. Mater. Interf. 2, 230-235, and references therein.

Mills, A., Hill, C., Robertson, P., 2012. Overview of the current ISO tests for photocatalytic materials. J. Photochem. Photobiol. A 237, 7-23.

Nadtochenko, V., Kiwi, J., 1997. Photoinduced adduct formation between Azo-dye Orange II and $\left[\mathrm{Fe}^{3+}(\mathrm{aq})\right]$ or $\mathrm{Fe}(\mathrm{ox})_{3} 3-/ \mathrm{H}_{2} \mathrm{O}_{2}$, photocatalytic degradation and laser spectroscopy. J. Chem. Soc. Faraday Trans. 93, 2373-2378.

Ollis, D.F., Ekabi, H.A., 1993. Photocatalytic Purification and Treatment of Water and Air. Elsevier Science Pub, B. V., Amsterdam.

Page, K., Wilson, M., Parkin, P.I., 2009. Antimicrobial surfaces and their potential in reducing the role of the inanimate environment in the incidence of hospital-acquired infections. J. Mater. Chem. 19, 38193831.

Page, K., Wilson, M., Mordan, N., Chrzanowski, W., Knowles, J., Parkin, P.I., 2011. Study of the adhesion of staphylococcus aureus to coated glass substrates. J. Mater. Sci. 46, 6355-6363.

Pigeot-Rémy, S., Simonet, F., Errazuriz-Cerda, E., Lazzaroni, J.C., Atlan, D., Guillard, C., 2011. Photocatalysis and disinfection of water: identification of potential bacterial targets. Appl. Catal. B: Environ. 104, 390-398.

Pitter, F., Chudoba, J., 1990. Biodegradability of Organic Substancesin the Aquatic Environment. CRC Press, Boca Raton, Florida.

Pulgarin, C., Kiwi, J., Nadtochenko, V., 2012. Mechanism of the photocatalytic destruction of bacteria by $\mathrm{TiO}_{2}$ films leading to cellwall damages and bacterial lysis. Appl. Catal. B 128, 179-183.

Rtimi, S., Baghriche, O., Pulgarin, C., Sanjines, R., Kiwi, J., $2012 \mathrm{a}$. Design, testing and characterization of innovative $\mathrm{TiN}-\mathrm{TiO}_{2}$ surfaces inactivating bacteria under low intensity visible light. RSC Adv. 2, 8591-8595.

Rtimi, S., Baghriche, O., Sanjines, R., Pulgarin, C., Ben-Simon, M., Lavanchy, J.-C., Houas, A., Kiwi, J., 2012b. Photocatalysis/catalysis by innovative $\mathrm{TiN}$ and $\mathrm{TiN}-\mathrm{Ag}$ surfaces inactivate bacteria under visible light. Appl. Catal. B: Environ. 123-124, 306-315.

Shirley, D., 1972. Corrections of electrostatic charged species in SPspectroscopy. Phys. Rev. B5, 4709-4716.

Subramanian, B., Muraleedharan, C., Annanthakumar, R., Jayachandran, M., 2011. A comparative study of TiN, TiON and TiAlN as surface coatings for bioimplants. Surf. Coat. Technol. 205, 5014 5020 .

Thüringer Surface and Biomaterials Kolloquium, September 2011. Zeulenroda, Germany.

Valentin, C., Pacchioni, G., Selloni, A., Livraghi, S., Giamello, E., 2005. Characterization of paramagnetic species in n-doped $\mathrm{TiO}_{2}$ Powders by EPR spectroscopy and DFT calculations. J. Phys. Chem. B 109, 11414-11419.

Wagner, D., Riggs, M., Davis, E., Müllenberg, G., 1979. Handbook of Xray Photoelectron Spectroscopy. Perkin-Elmer Corporation Physical Electronics Division, Minnesota.

Wang, Y., Hang, K., Anderson, N.A., Lian, T., 2003. Comparison of electron transfer dynamics in molecule-to-nanoparticle and intramolecular charge transfer complexes. J. Phys. Chem. B 107, 9434-9440.

Yates, M.H., Brook, A.L., Ditta, B.I., Evans, P., Foster, H.A., Sheel, D.W., Steele, A., 2008. Photo-induced self-cleaning and biocidal behaviour of titania and copper oxide multilayers. J. Photochem. Photobiol. A 197, 197-208. 